\title{
Clinico-radiological study of collateral circulation after internal carotid and middle cerebral occlusion
}

\author{
M. GADO AND JOHN MARSHALL
}

From the Institute of Neurology, National Hospitals for Nervous Diseases, Queen Square, London

\begin{abstract}
SUMMARY The intracranial collateral channels apart from the circle of Willis have been studied angiographically in 34 patients with internal carotid artery occlusion and 19 with occlusion of the middle cerebral artery. These collaterals are present in a high percentage of cases within a week of the ictus and are more common when the stroke has developed slowly. Their presence in occlusion of the middle cerebral artery seems to offer some protection against infarction but in internal carotid artery occlusion they are less important than the circle of Willis and when present suggest inadequacy of this structure.
\end{abstract}

It is an established fact that the human cerebral circulation is provided with collateral pathways and that their efficiency plays an essential role in the compensatory adjustment of blood flow to the brain in the event of vascular occlusion. The introduction of cerebral angiography made it possible to detect vascular occlusions in the living subject and to demonstrate the collateral pathways which may have developed. Angiography may also reveal evidence of the infarction which may follow an occlusion.

The clinical consequences of vascular occlusion vary from the complete absence of any defect to severe disability. The occlusion of one internal carotid artery, for example, may be unaccompanied by symptoms until occlusion of the opposite internal carotid artery occurs. The later incident may, or may not, present with a severe stroke. Fields, Edwards, and Crawford (1961) described 16 cases of bilateral internal carotid occlusion, only 10 of whom presented with a stroke, the remaining six showing only minimal deficit. Doniger (1963) described a patient with bilateral carotid and basilar artery occlusions who had only minor impairment. Angiography in this patient showed filling of the anterior and middle cerebral arteries on both sides via the ophthalmic arteries which were hypertrophied. The posterior cerebral arteries and the terminal basilar artery filled via the anastomosis between the posterior inferior cerebellar artery and the corresponding superior cerebellar artery on each side. The patient had a 10 year history of transient ischaemic attacks and was admitted after a stroke from which she made marked recovery. There must be a relationship between the degree of neurological deficit after a vascular occlusion and the efficiency of the collateral arteries in re-establishing the circulation in the affected territory.

The practical value of the radiological demonstration of collateral circulation is subject to severe limitations. The angiogram cannot provide answers to such questions as: (1) Was the occlusion sudden or gradual, giving time for the collaterals to adapt to the needs of the cerebral circulation? (2) How soon after occlusion did collateral flow take place? (3) Was the collateral flow established before irreparable damage had been done?

Yet the answers to such questions have an important bearing on the clinical outcome and prognosis. The present study was undertaken in order to define more closely the factors governing the development of collateral circulation as seen radiologically and its relationship to the clinical state.

\section{PATIENTS}

A series of 53 patients, 34 with occlusion of the internal carotid artery, and 19 with occlusion of the middle cerebral artery have been studied. Occlusion was defined as complete obstruction of the lumen of the artery.

As the patency or otherwise of the circle of Willis cannot be demonstrated by unilateral carotid angiography (which was the method of examination employed in these cases), study of the collateral circulation in the cases of internal carotid occlusion was confined to what may be conveniently called 'the small vessel collaterals'. These can be divided into two groups: 
1. Anastomoses between branches of the carotid siphon and branches of the external carotid artery comprising:

a. Anastomosis between the ophthalmic artery
(Fig. 1) and the superficial temporal, middle meningeal, and internal and external maxillary branches of the external carotid artery.

b. Anastomoses between the carotico-tympanic

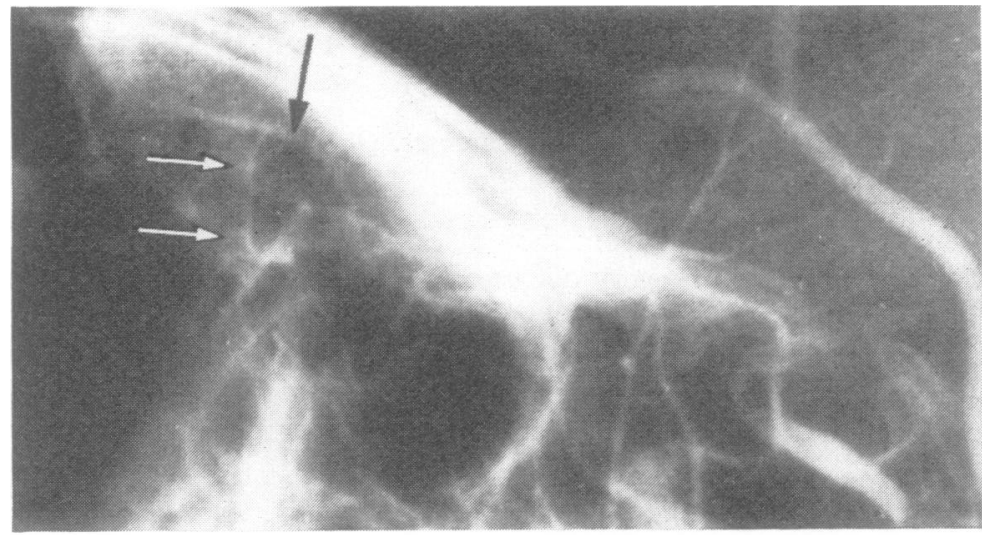

a. Early in the arterial phase, there is faint filling of the distal branches of the ophthalmic artery. There is also filling of the siphon via the carotico-tympanic anastomosis.

b. One second later, retrograde

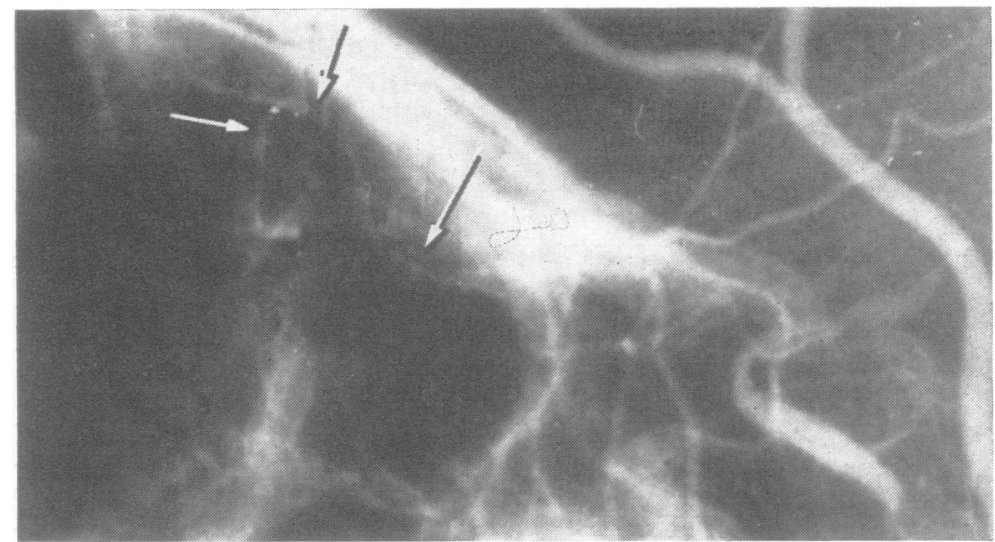
flow in the ophthalmic artery which now appears opacified throughout its length.

c. Three seconds later the ophthalmic artery is no longer opacified because the external carotid branches are no longer opacified. The carotid siphon is still filled.

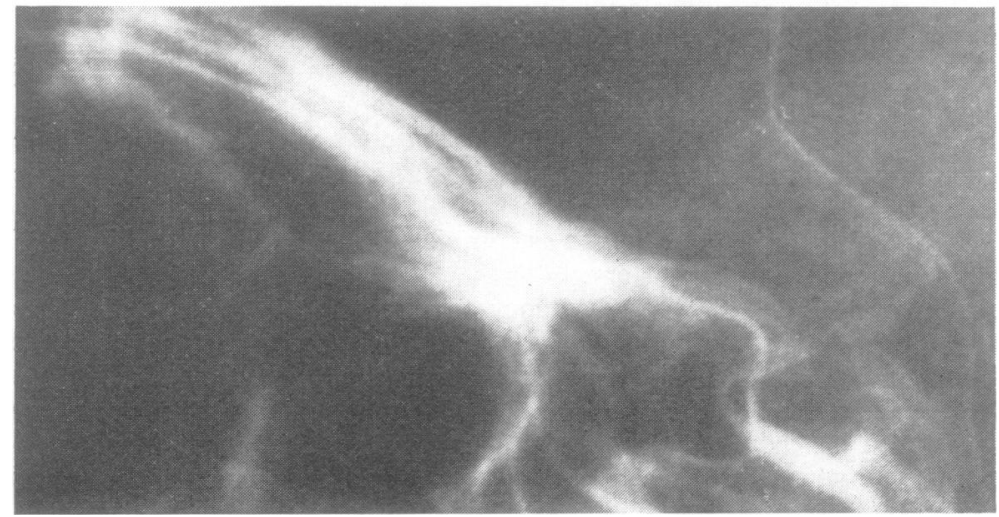

FIG. 1. A.C., female aged 56. Right internal carotid artery occlusion. Right carotid angiogram. 
(Fig. 2) on the one hand, and the stylomastoid branch of the posterior auricular artery and the anterior tympanic branch of the internal maxillary artery on the other, these again being branches of the external carotid artery. The carotico-tympanic artery is normally small and difficult to identify on an angiogram but after internal carotid occlusion it becomes prominent.

c. Anastomosis between the artery to the inferior cavernous sinus branch of the carotid siphon (Fig. 3) on the one hand and the middle meningeal and accessory meningeal arteries on the other hand (Margolis and Newton, 1969).

2. Anastomoses between the meningeal branches of the external carotid artery and the cortical leptomeningeal branches of the cerebral vessels (Fig. 4).

In the cases of occlusion of the middle cerebral artery the collaterals studied were the cortical leptomeningeal end-to-end anastomoses (Fig. 5) between the anterior and middle and the posterior and middle cerebral arteries (Mount and Taveras, 1957). Anastomoses between branches of one main cerebral artery are rare (Welch, Stephens, Huber, and Ingersoll, 1955; Hawkins, 1966).

\section{RESULTS}

In the 34 cases of internal carotid artery occlusion, collateral circulation via the ophthalmic artery was demonstrated in $26(76 \%)$ and that via the other two branches of the carotid siphon in $17(50 \%)$; most of the latter (13) showed ophthalmic collateral flow as well. The anastomosis between the branches of the external carotid artery and the cortical leptomeningeal branches of the internal carotid artery was demonstrated in two cases $(6 \%)$.

Of the 19 cases with occlusion of the middle cerebral artery, 13 showed cortical leptomeningeal anastomoses with branches of the anterior cerebral artery. In one of these patients the proximal segment of the anterior cerebral artery was hypoplastic, the artery filling from the other side as was demonstrated by bilateral angiography.

Estimation of the frequency of cortical leptomeningeal anastomoses with branches of the posterior cerebral artery in cases of middle cerebral artery occlusion is more difficult, because the posterior cerebral artery normally fills in only about $30 \%$ of carotid angiograms. In the presence of a middle cerebral artery occlusion this percentage is increased, reaching $42 \%$ in our series. Moreover, when the occlusion is placed distal to the trifurcation, the posterior branches of the middle cerebral artery may be spared; this was the case in $25 \%$ of our series, so that collateral circulation with the posterior cerebral artery was not then in question (Fig. 6).

The influence of previous completed strokes or transient ischaemic attacks (TIAs) in promoting the development of the collateral circulation was examined, the results being given in Table 1 . There was no evidence that previous ischaemic episodes had promoted the development of collaterals or, if they had, the collateral circulation had been overtaken by the advance of the vascular disease by the time the later episode occurred.

The effect of the type of stroke upon the develop-

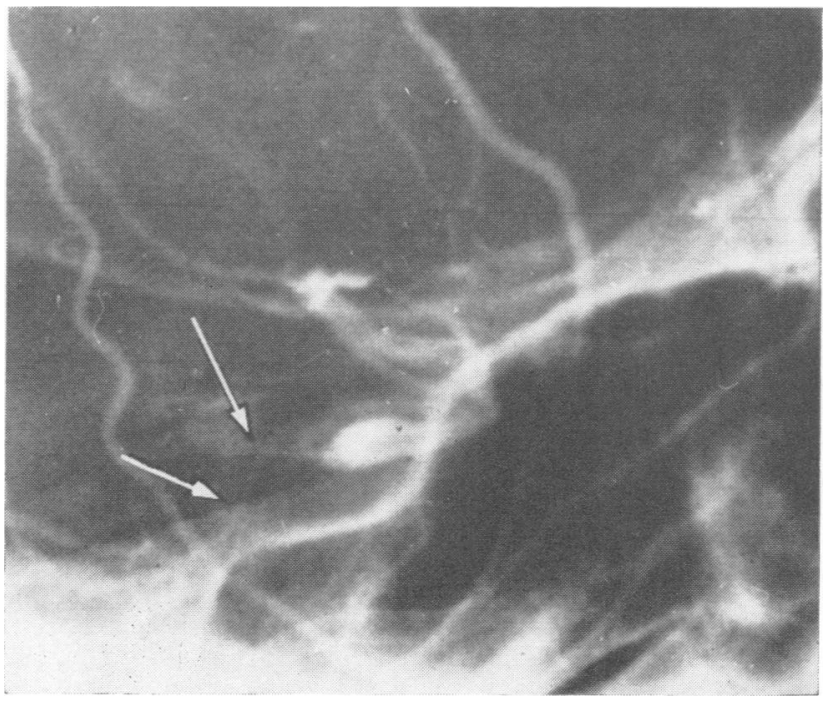

FIG. 2. E.C., male aged 62. Left carotid angiogram showed occlusion of the left internal carotid in the neck. The carotico-tympanic branch of the siphon is seen filling the siphon distal to the point where it joins it. Proximally, there is no filling of the internal carotid artery between the site of the occlusion and the take off of the carotico-tympanic branch. Note the dye in the branches of the middle cerebral artery. 


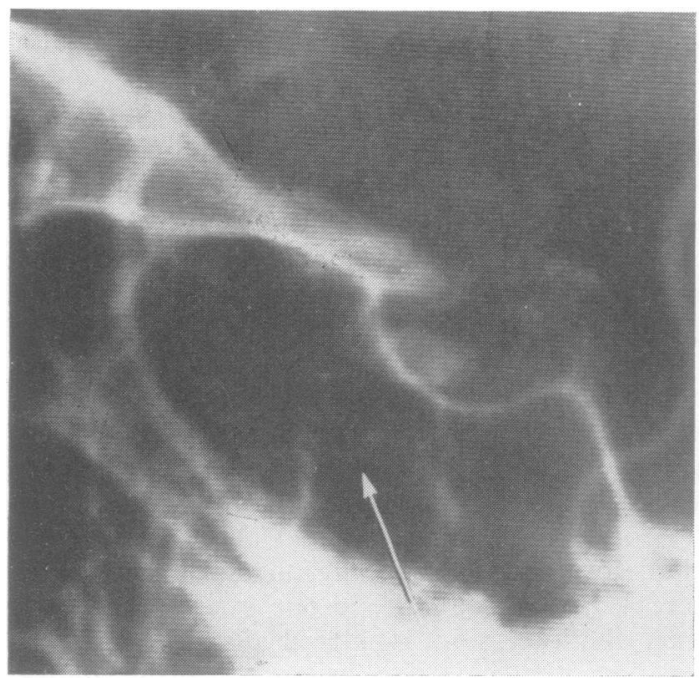

(a)

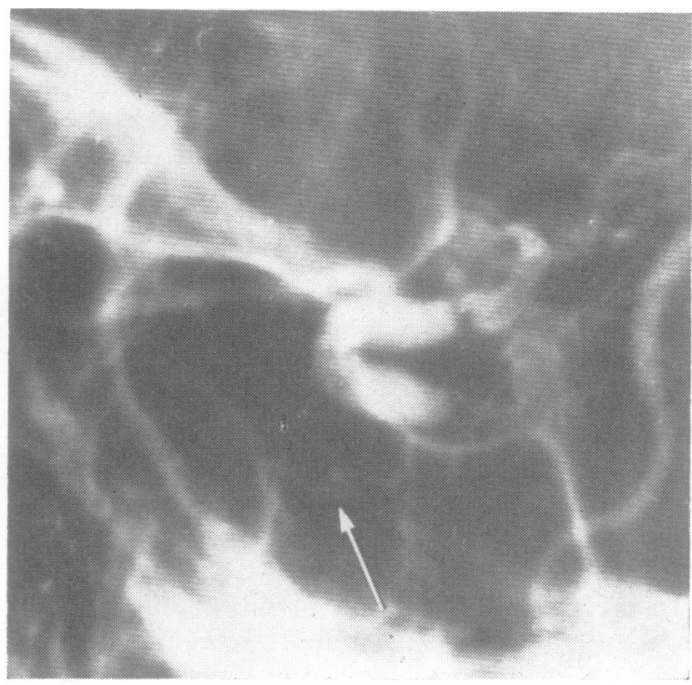

(b)

FIG. 3. D.D., female aged 45. Right carotid angiogram showed occlusion of the internal carotid artery in the neck.

a. Early in the series there is filling of the branch to the inferior cavernous sinus and the distal part of the ophthalmi? i artery from the branches of the external carotid artery. Early filling of the siphon from the branch to the cavernoli $\vec{B}$ sinus is noted.

b. A later stage of the series shows retrograde flow in the ophthalmic artery with further filling of the siphon ant branches of the middle cerebral artery.

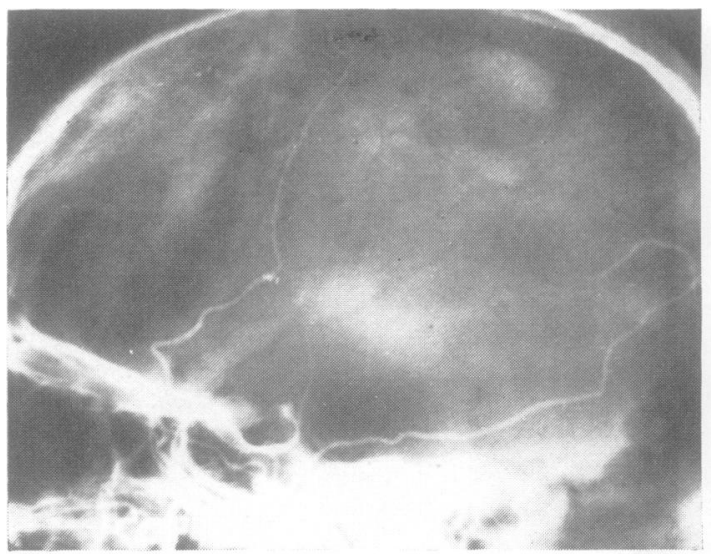

(a)

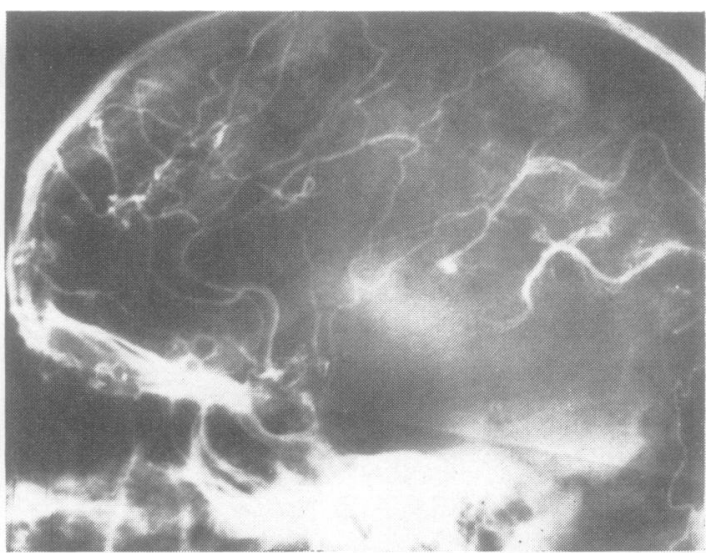

(b)

FIG. 4. B.W., female aged 47. Bilateral internal carotid artery occlusion. Right carotid angiogram. (a) Early in the N series, there is filling of the branches of the external carotid artery only. Note the prominence of the meningeal vessels. $N$ (b) The later film shows retrograde filling of the cortical branches of the anterior and middle cerebral arteries via anastomoses with the meningeal branches of the external carotid artery. 


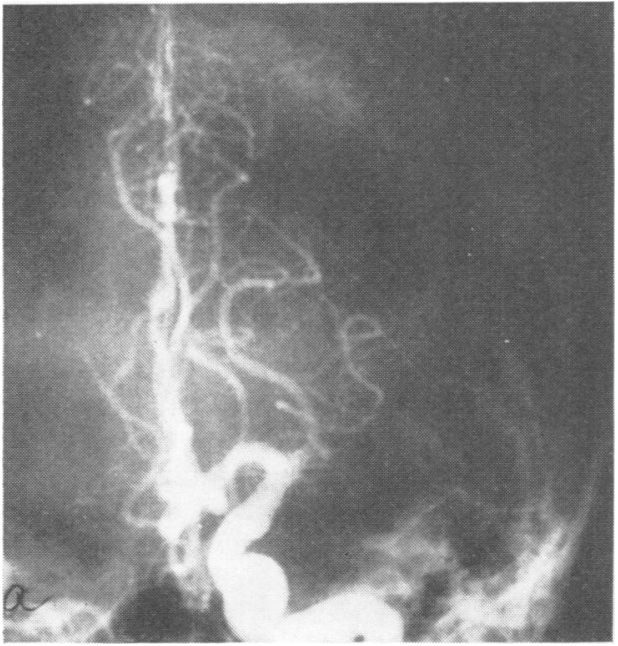

FIG. 5a.

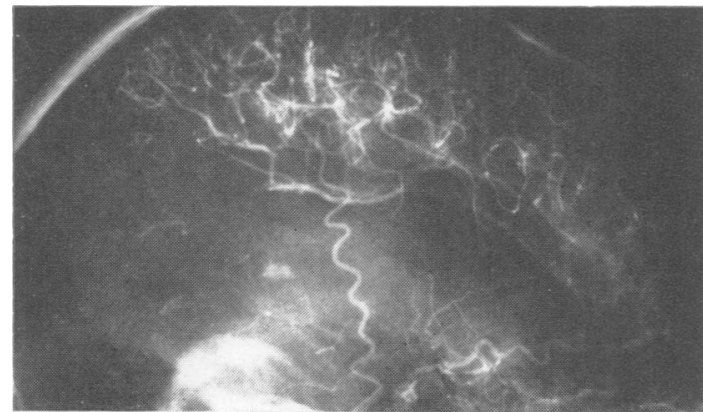

FIG. 5c.

FIG. 5. F.C., male aged 64. Left middle cerebral artery occlusion. Left carotid angiogram. (a) A.P. view shows occlusion of the middle cerebral artery close to its origin. (b) Lateral view. The first film in the arterial phase shows no visualization of middle cerebral artery branches; the posterior cerebral artery is filled. (c and d) The later films show retrograde filling of the branches of the middle cerebral artery via lepto-meningeal anastomoses with cortical branches of the anterior and posterior cerebral arteries.

ment of collateral vessels was next examined, the cases being divided into completed strokes, strokesin-evolution, and TIAs. As Table 2 shows, there is evidence that the gradual development of the strokein-evolution provides more time for the development of the collateral circulation. It should also be noted that in cases of internal carotid artery occlusion the frequency of collaterals was higher in completed strokes than in TIAs.

Evidence about the speed of development of collateral arteries was sought by separating the

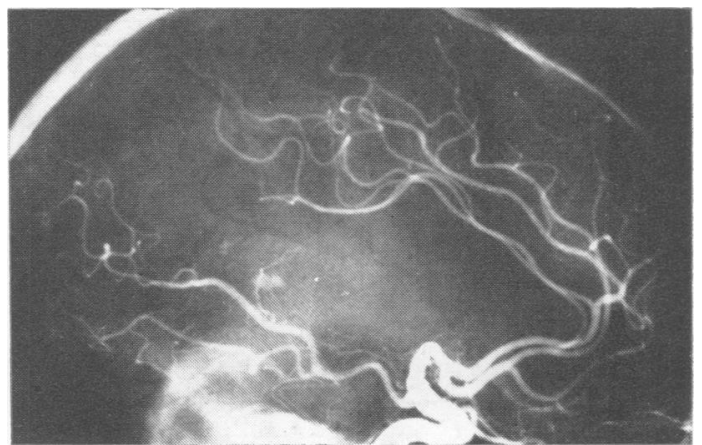

FIG. $5 b$.

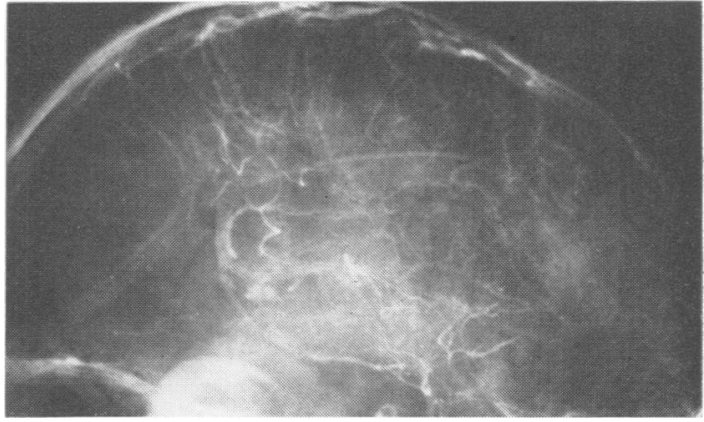

FIG. $5 \mathrm{~d}$.

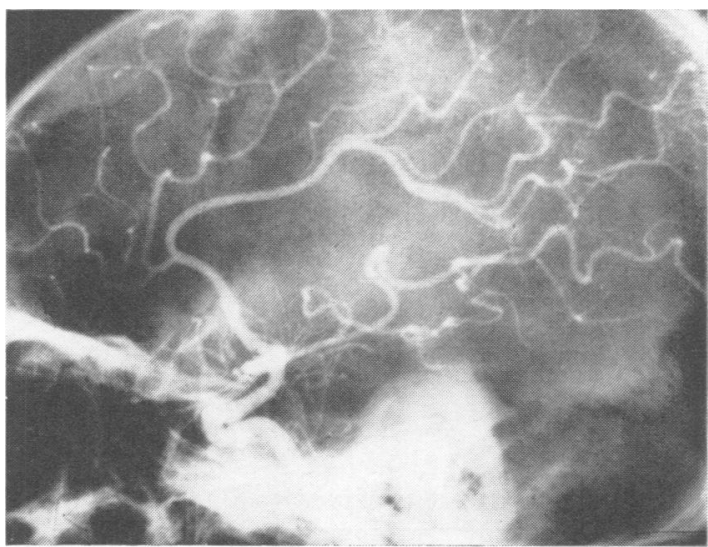

FIG. 6. H.H., male aged 44. Right middle cerebral artery occlusion. Right carotid angiogram, lateral view. The terminal branches of the middle cerebral artery are well filled while the insular vessels are not opacified. The occlusion occurred distal to the take-off of the terminal branches from the stem of the middle cerebral artery. 
TABLE 1

RELATIONSHIP BETWEEN PREVIOUS ISCHAEMIC EPISODES AND THE DEVELOPMENT OF COLLATERALS

\begin{tabular}{lccccc}
\hline & \multicolumn{2}{c}{ No previous episodes } & & \multicolumn{2}{c}{ Previous episodes } \\
\cline { 2 - 3 } \cline { 5 - 6 } & $\begin{array}{l}\text { Internal } \\
\text { carotid } A .\end{array}$ & $\begin{array}{c}\text { Middle } \\
\text { occlusion }\end{array}$ & $\begin{array}{c}\text { cerebral } \text { Anternal } \\
\text { occlusion }\end{array}$ & $\begin{array}{c}\text { carotid } A . \\
\text { occlusion }\end{array}$ & $\begin{array}{c}\text { Middle } \\
\text { cerebral } A . \\
\text { occlusion }\end{array}$ \\
\hline $\begin{array}{l}\text { No. of cases } \\
\text { No. showing }\end{array}$ & 24 & 12 & 10 & 7 \\
$\begin{array}{l}\text { collaterals } \\
\text { Percentage }\end{array}$ & 20 & 80 & 67 & 80 & 5 \\
\hline
\end{tabular}

cases according to the interval which had elapsed between the clinical onset of the ischaemic event and the angiography. Table 3 shows that over $80 \%$ of those examined within the first week had collaterals, the percentage being lesser rather than greater among those examined at a later date.

The influence of radiological evidence of infarction upon the development of collateral vessels was also studied. Positive evidence of infarction is provided by the following signs (Taveras, Gilsom, Davis, Kilgore, and Rumbaugh, 1969). (1) arteriolarcapillary block as shown by extreme prolongation of the arterial phase (Fig. 7); (2) swelling of the hemisphere indicated by shift of midline vessels; (3) persistent vasodilatation revealed by capillary blush, early filling veins, and prominence of the lenticulostriate arteries.

These signs cannot be elicited by unilateral carotid angiography on the side of an internal carotid artery occlusion because filling of the siphon via collaterals usually leads to visualization of the middle cerebral artery only, and even this vessel may fill only transiently because of dilution of the dye by blood from the anterior and posterior communicating arteries. For this reason the correlation between the presence of collaterals and radiological evidence of infarction was made only in the 19 patients with occlusion of the middle cerebral artery. Of the 19 patients 15 showed angiographic evidence of infarction, only nine of whom had collaterals. On the other hand collaterals were present in all four of the patients who had no radiological signs of infarction.

As all but two of the patients in the entire series had a diastolic blood pressure under $100 \mathrm{~mm} \mathrm{Hg}$ it was not possible to compare the effect of the presence or absence of hypertension on the development of the collateral circulation.

\section{DISCUSSION}

Although the various examples of collateral circulation examined here have been documentedi previously (Fields et al., 1965) the factors governini $\vec{\rho}$ their development and their exact relationship to the $\mathrm{c}$ clinical status of the patient has received little attention. This is not surprising in view of the technical difficulties which have been mentioned and the obvious complexity of the relationship Nevertheless, if the prevention and treatment of $\vec{v}$ cerebrovascular disease is to advance, the importan

TABLE 2

RELATIONSHIP BETWEEN TYPE OF STROKE AND COLLATERALS

\begin{tabular}{|c|c|c|c|c|c|c|}
\hline & \multicolumn{2}{|c|}{$\begin{array}{c}\text { Group } 1 \\
\text { Complete stroke }\end{array}$} & \multicolumn{2}{|c|}{$\begin{array}{c}\text { Group } 2 \\
\text { Stroke-in-evolution }\end{array}$} & \multicolumn{2}{|c|}{$\underset{T I A}{\text { Group } 3}$} \\
\hline & $\begin{array}{l}\text { Internal } \\
\text { carotid } A . \\
\text { occlusion }\end{array}$ & $\begin{array}{c}\text { Middle } \\
\text { cerebral } A . \\
\text { occlusion }\end{array}$ & $\begin{array}{l}\text { Internal } \\
\text { carotid } A . \\
\text { occlusion }\end{array}$ & $\begin{array}{l}\text { Middle } \\
\text { cerebral } A . \\
\text { occlusion }\end{array}$ & $\begin{array}{l}\text { Internal } \\
\text { carotid } A . \\
\text { occlusion }\end{array}$ & $\begin{array}{c}\text { Middle } \\
\text { cerebral } \\
\text { occlusion }\end{array}$ \\
\hline $\begin{array}{l}\text { No. of cases } \\
\text { No. showing collaterals } \\
\text { Percentage }\end{array}$ & $\begin{array}{l}18 \\
15 \\
83\end{array}$ & $\begin{array}{r}14 \\
9 \\
64\end{array}$ & $\begin{array}{r}9 \\
9 \\
100\end{array}$ & $\begin{array}{r}4 \\
4 \\
100\end{array}$ & $\begin{array}{r}7 \\
5 \\
71\end{array}$ & $\begin{array}{l}\text { ? } \\
?\end{array}$ \\
\hline
\end{tabular}

TABLE 3

RELATIONSHIP BETWEEN TIME LAPSE SINCE CLINICAL ONSET AND APPEARANCE OF COLLATERALS

\begin{tabular}{|c|c|c|c|c|c|c|}
\hline \multirow{2}{*}{$\begin{array}{l}\text { Time lapse between } \\
\text { clinical onset and angiography }\end{array}$} & \multicolumn{2}{|c|}{ Less than 1 week } & \multicolumn{2}{|c|}{ 1-4 weeks } & \multicolumn{2}{|c|}{ More than 4 weeks } \\
\hline & $\begin{array}{l}\text { Internal } \\
\text { carotid } A . \\
\text { occlusion }\end{array}$ & $\begin{array}{c}\text { Middle } \\
\text { cerebral } A . \\
\text { occlusion }\end{array}$ & $\begin{array}{l}\text { Internal } \\
\text { carotid } A . \\
\text { occlusion }\end{array}$ & $\begin{array}{c}\text { Middle } \\
\text { cerebral } A . \\
\text { occlusion }\end{array}$ & $\begin{array}{c}\text { Internal } \\
\text { carotid } A . \\
\text { occlusion }\end{array}$ & $\begin{array}{c}\text { Middle } \\
\text { cerebral A. } \\
\text { occlusion }\end{array}$ \\
\hline $\begin{array}{l}\text { No. of cases } \\
\text { No. showing collaterals } \\
\text { Percentage }\end{array}$ & $\begin{array}{l}12 \\
10 \\
83\end{array}$ & $\begin{array}{r}11 \\
9 \\
82\end{array}$ & $\begin{array}{r}12 \\
9 \\
75\end{array}$ & $\begin{array}{r}2 \\
1 \\
50\end{array}$ & $\begin{array}{r}10 \\
7 \\
70\end{array}$ & $\begin{array}{r}4 \\
4 \\
100\end{array}$ \\
\hline
\end{tabular}




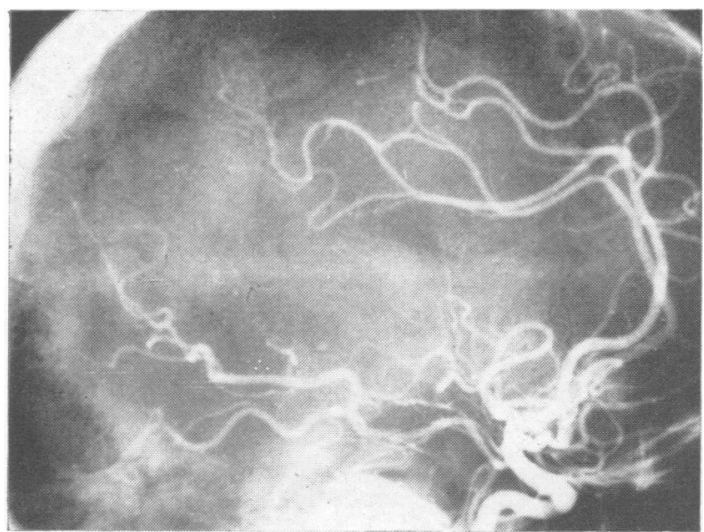

FIG. 7a.

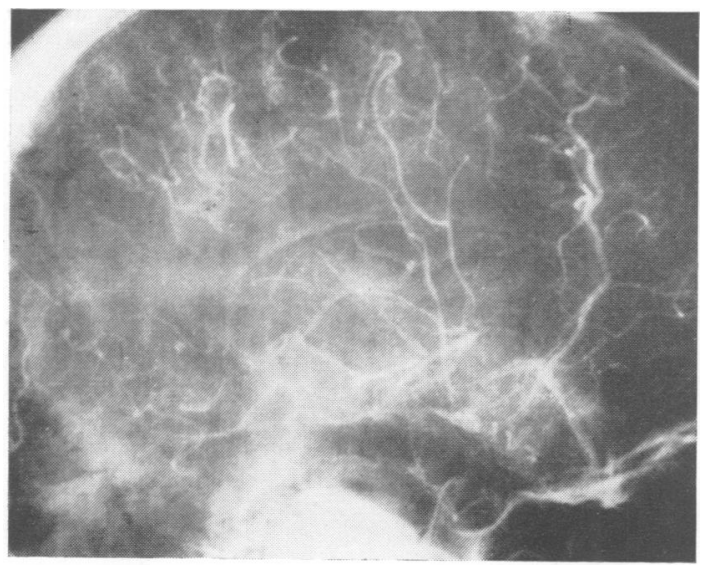

FIG. 7b.

factor of the collateral circulation must be better understood.

It might be expected that previous ischaemic episodes would act as a stimulus to the development of collateral circulation but there was no evidence in the present study to support this view. This may reflect relentless progression of the underlying vascular disease, which may have obliterated previously developed collateral vessels. This would accord with Marquardsen's (1969) study of mortality in patients with cerebrovascular disease which proceeded at a steady $16 \%$ per year for men and $18 \%$ a year for women, regardless of intercurrent events, cerebrovascular or otherwise. It certainly underlines the need to relieve stenoses whenever possible after an ischaemic event, as recovery from such an event does not necessarily indicate that the patient has gained collateral vessels or that, if he has, they will remain patent.

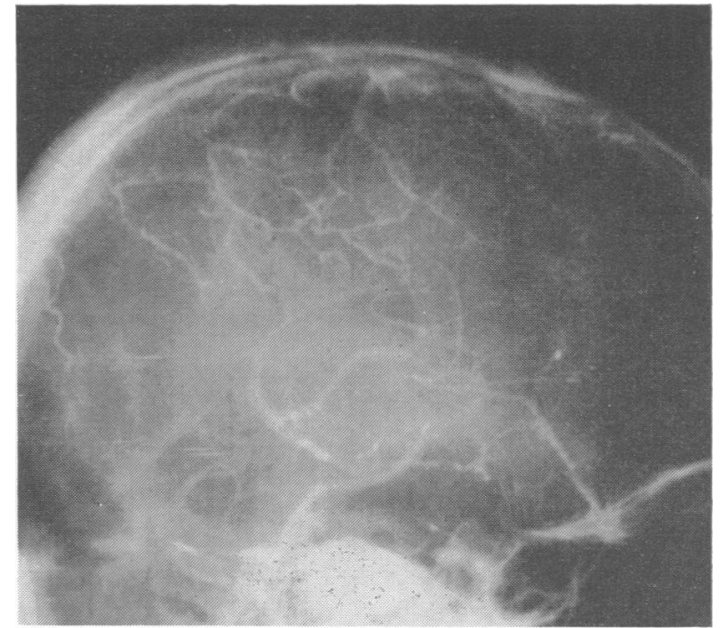

FIG. 7c.

FIG. 7. D.D., male aged 21. Left middle cerebral artery occlusion. Left carotid angiogram, lateral series.

(a) In the arterial phase, there is filling of a few branches of the middle cerebral artery.

(b) In the capillary phase 2.5 seconds later, there is retrograde filling of the ascending frontal and parietal branches via anastomoses with the cortical branches of the anterior cerebral artery.

(c) 4.5 seconds later, in the venous phase, dye is still seen in the branches of the middle cerebral artery.

The time factor in the development of collateral vessels is clearly of importance. Contrary to the experience of Denny-Brown (1951) who thought that small vessel anastomoses cannot be demonstrated within six weeks of the ictus, they were present in the present series in $80 \%$ of those examined within the first week. They were also more frequent when the stroke had developed slowly than in the more rapidly developing completed stroke. This suggests the need to treat all cerebral ischaemic episodes, particularly transient events, as a matter of urgency, avoiding all measures which may compromise the circulation during the vital first few days, so as to give maximum opportunity for the development of the collateral circulation.

In the cases of internal carotid artery occlusion, small vessel collaterals were seen more commonly in completed strokes and in strokes-in-evolution than in TIAs as previously found by Pitts (1962). Since it is reasonable to assume that the circle of Willis plays the major part in providing collateral circulation in cases of internal carotid occlusion, Pitts has suggested that the presence of small vessel collaterals indicates inadequacy in the circle, a fact 
which would account for their increased frequency in completed strokes. A similar view was put forward by Bossi and Pasani (1965). This may be helpful in prognosis and certainly needs to be borne in mind when planning surgical treatment and would be an indication for angiographic examination of the circle of Willis.

In contrast to the situation in internal carotid artery occlusion, the small vessel collaterals are the only available source of collateral flow in cases of middle cerebral artery occlusion. This explains why all patients without angiographic signs of infarction had well-developed collaterals and their absence from a considerable proportion of the cases with evidence of infarction.

While small vessel collaterals are best demonstrated by carotid angiography, the circle of Willis can be assessed only by three or four vessel angiography. More extensive investigation than is needed to demonstrate the site of an occlusion is clearly required for complete assessment of the collateral circulation. This may be contraindicated for general reasons in some cases. Yet if the many currently ill-understood and unpredictable features of cerebrovascular disease are to yield helpful information in prognosis and treatment, this assessment must be attempted in suitable cases such as the younger victims of premature atherosclerosis.

We wish to thank Dr. J. W. D. Bull in whose department the angiographic studies were made.

\section{REFERENCES}

Bossi, R., and Pasani, C. (1955). Collateral cerebral circulation through the ophthalmic artery and its efficiency in internal carotid occlusion. Brit. J. Radiol., 28, 462-469.

Denny-Brown, D. (1951). Symposium on specific methods of treatment; treatment of recurrent cerebrovascular symptoms and questions of 'vasospasm'. Med. Clin. N. Amer., 35, $1457-1474$.

Doniger, D. E. (1963). Bilateral complete carotid and basilar artery occlusion in a patient with minimal deficit. Case report and discussion of diagnostic and therapeutic implications. Neurology (Minneap.), 13, 673-678.

Fields, W. S., Bruetman, M. E., and Weibel, J. (1965). Collateral Circulation of the Brain. Williams and Wilkins: Baltimore.

Fields, W. S., Edwards, W. H., and Crawford, E. S. (1961). Bilateral carotid artery thrombosis. Arch. Neurol. (Chic.), 4, 369-383.

Hawkins, T. D. (1966). The collateral anastomoses in cerebrovascular occlusion. Clin. Radiol., 17, 203-219.

Margolis, M. T., and Newton, T. H. (1969). Collateral pathways between the cavernous portion of the internal carotid and external carotid arteries. Radiology, 93, 834-836.

Marquardsen, J. (1969). The Natural History of Acute Cerebrovascular Disease. Munksgaard: Copenhagen.

Mount, L. A., and Taveras, J. M. (1957). Arteriographic demonstration of the collateral circulation of the cerebral hemispheres. Arch. Neurol. Psychiat. (Chic.), 78, 235-253.0

Pitts, F. W. (1962). Variations of collateral circulation iఠ ?internal carotid occlusion. Comparison of clinical an $\bar{\phi}$ X-ray findings. Neurology (Minneap.), 12, 467-471.

Taveras, J. M., Gilsom, J. M., Davis, D. O., Kilgore, B $\underset{\Omega}{\mathbb{\Phi}}$ 을 and Rumbaugh, C. L. (1969). Angiography in cerebrat infarction. Radiology, 93, 549-558.

Welch, K., Stephens, J. W., Huber, W., and Ingersoll, Cृ으 (1955). Collateral circulation following middle cerebr迎 branch occlusion. J. Neurosurg., 12, 361-368. 